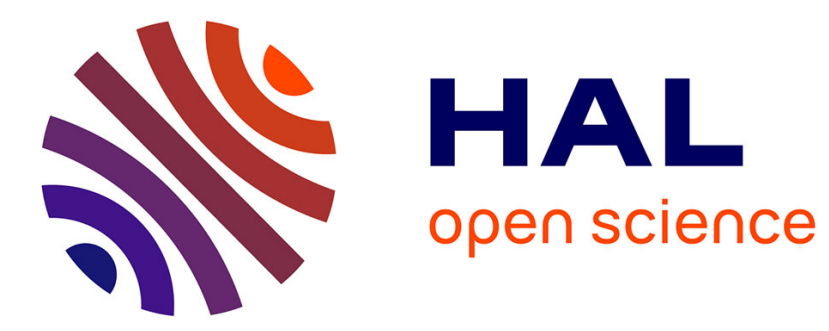

\title{
Thermal oxidation of clay-nanoreinforced polypropylene
}

Giovanna Gutiérrez, Bruno Fayolle, Gilles Regnier, Jorge Alberto Medina

\section{To cite this version:}

Giovanna Gutiérrez, Bruno Fayolle, Gilles Regnier, Jorge Alberto Medina. Thermal oxidation of clay-nanoreinforced polypropylene. Polymer Degradation and Stability, 2010, 95 (9), pp.1708-1715. 10.1016/j.polymdegradstab.2010.05.020 . hal-02456170

\section{HAL Id: hal-02456170 https://hal.science/hal-02456170}

Submitted on 27 Jan 2020

HAL is a multi-disciplinary open access archive for the deposit and dissemination of scientific research documents, whether they are published or not. The documents may come from teaching and research institutions in France or abroad, or from public or private research centers.
L'archive ouverte pluridisciplinaire HAL, est destinée au dépôt et à la diffusion de documents scientifiques de niveau recherche, publiés ou non, émanant des établissements d'enseignement et de recherche français ou étrangers, des laboratoires publics ou privés. 


\title{
Thermal oxidation of clay-nanoreinforced polypropylene
}

\author{
G. Gutiérrez ${ }^{\mathrm{a}}$, F. Fayolle ${ }^{\mathrm{a}, *}$, G. Régnier ${ }^{\mathrm{a}}$, J. Medina ${ }^{\mathrm{b}}$ \\ a Laboratoire Procédés et Ingénierie en Mécanique et Matériaux, PIMM (CNRS UMR 8006), Arts et Métiers ParisTech, 151 Bvd de l'Hôpital, 75013 Paris, France \\ ${ }^{\mathrm{b}}$ Universidad de los Andes, Grupo de Materiales y Manufactura CIPP - CIPEM, Crr 1a este N 19 A - 40, Bogotá, D.C., Colombia
}

Keywords:

Polypropylene

Nanocomposite

Micro ATR-FTIR

Oxidation profiles

Modeling

\begin{abstract}
A B S T R A C T
The thermo-oxidation process at low temperatures for a montmorillonite-nanoreinforced polypropylene $(P P)$ was studied. Experimental aging kinetic data at 100,80 and $60^{\circ} \mathrm{C}$ have been obtained and compared with a computational simulation in which a kinetic model based on the closed loop approach was used. As a result, it has been found that the montmorillonite role is not limited to a role of inert filler in the polymer matrix but induces a slight catalytic effect leading to induction period reduction. This effect has been well simulated by increasing initial hydroperoxyde concentration. The consequences of kinetic control by oxygen diffusion have also been investigated by using micro ATR-FTIR mapping to assess concentration profiles of the oxidation products across the sample thickness. It has been found that the oxidized layer thickness is close to $17 \mu \mathrm{m}$ for the pure polypropylene whereas it is around $10 \mu \mathrm{m}$ for the nanocomposite at $100{ }^{\circ} \mathrm{C}$. These profile variations have been attributed to differences in oxygen diffusion coefficient values. Simulations based on the kinetic model including diffusion-reaction coupling describe these profiles well.
\end{abstract}

\section{Introduction}

Nanocomposite materials are attracting great interest in the search for better performing materials with improved thermal, mechanical, electrical and barrier properties. Using plastics as a matrix in this technology is advantageous due to their capability to improve such properties by incorporating nanofiller quantities lower than the $20 \%$ vol. required by conventional fillers such as talc, calcium carbonate, and glass fibers [1-3]. Higher aspect ratios as provided with the use of layer silicates allow stronger interfacial clay/polymer interactions [4-7], justifying the use of such silicates as fillers.

The aging process induced by photooxidation in polymermatrix nanocomposites has been studied by several researchers. Through those studies it was found that the incorporation of nanoclays does not change the aging mechanism of the composite, but rather decreases its induction time, meaning that the montmorillonite (MMT-O) essentially accelerates the oxidation process [8-10]. In the case of thermo-oxidation there is only a small number of studies on the aging kinetics of nanofilled PP. Work by Lomakin - concerning the tracking of weight loss for a nanocomposite during the thermo-oxidation process at temperatures higher than $250^{\circ} \mathrm{C}$ by using thermal analysis [11 ] - or by Vyazovkin -

\footnotetext{
* Corresponding author. Tel.: +33 14424 6149; fax: +3314424 6382 .

E-mail address: bruno.fayolle@paris.ensam.fr (F. Fayolle).
}

applying a classical kinetic approach [12] - or by Bertini et al. in which the thermal degradation of a montmorillonite-reinforced polypropylene is studied by TGA and DTG techniques [13] provided key insight. However, the results of these studies were obtained far above the usual temperature interval for the use of PP. To our knowledge, no studies on the thermo-oxidation mechanisms and kinetics in solid state at moderate temperatures exist in the literature.

Concerning a general strategy for studying the thermal oxidation of organic composites, an analytical methodology based on a classical oxidation scheme has been presented by Verdu [14]. From the pure $P P$ oxidation kinetic modeling point of view, a model including reaction-diffusion coupling has been used to simulate the thermal oxidation in air at $80-150{ }^{\circ} \mathrm{C}[15,16]$. Our aim in this paper is to apply both of these approaches to studying the thermal oxidation kinetics of polypropylene nanocomposites. In spite of its complexity, kinetic modeling of the oxidation remains of great interest for the prediction of end-product lifetime.

The aim of this work is to study the montmorillonite influence on the oxidation kinetics of polypropylene at moderated temperatures from experimental and theoretical points of view. The first step to accomplish this objective is compounding the material, which is one of the most critical stages, since good clay dispersion has to be reached in order to separate the clay sheets. To better split the nanosheets, the clay and coupling agent are pre-mixed. Next, the concentrate is blended with pure polypropylene to obtain the nanocomposite. After a complete material characterization using 
a flexible approach [17], the results from thermo-oxidation experiments are obtained. The first goal is to find possible differences between nanoreinforced and pure polypropylene. The second objective is to apply the kinetic model proposed elsewhere [15] to simulate nanocomposite thermal oxidation and to explore the influence of the oxygen diffusion coefficient changes on oxidation profiles of the sample when oxidation is diffusion controlled. Such influence will also be experimentally studied using a new FTIR imaging tool (see in Experimental part).

To follow the evolution of the oxidation process over time, infrared micro-spectrometry measurements in transmittance mode are often performed $[18,19]$. However, its spatial resolution of about 25-30 $\mu \mathrm{m}$ does not permit the measurement of oxidation layers, whose individual thickness is of the order or even lower than this resolution. To enhance lateral resolution, some experimental alternatives are available, such as the use of synchrotron radiation as a source for FTIR measurements [20]. By reducing the resolution with the use of high refractive index ATR crystals, attenuated total reflectance infrared spectrometry (ATR-FTIR) permitted us to follow the extent of oxidation in aged carbon-filled rubbers and polyethylene samples [21,22]. Several recent publications have used this approach [23-25]. Here, we applied this micro-ATR-FTIR approach to assess the oxidation profiles and the thickness of the oxidized layer by using a Perkin-Elmer SpotLight 300 FTIR Microscope with Spectrum 100 in ATR mode imaging showing spatial resolution of $6 \mu \mathrm{m}$.

\section{Experimental}

\subsection{Materials}

The matrix used was the Propilco 01R25 propylene-ethylene copolymer supplied by Propilco (MFI $0.8 \mathrm{~g} / 10 \mathrm{~min}$ ). The nanoclay was Nanofil ${ }^{\circledR}$ SE 3000, montmorillonite modified with di-tallow dimethyl quaternary ammonium salt (Specific weight: $1.2 \mathrm{~g} / \mathrm{cm}^{3}$ ) supplied by Süd Chemie AG. The coupling agent was the Polybond ${ }^{\circledR}$ $3200,1 \% \mathrm{w}$ maleic anhydride grafted propylene (MFI $115 \mathrm{~g} / 10 \mathrm{~min}$ ) provided by Cromtom. The proportion of MMT-O and coupling agent was $9.5 \%$ weight and $28.5 \%$ weight, respectively.

\subsection{Composition of the clay reinforced polypropylene}

The mixing of the materials was done in an internal Brabender Plasti-Corder PLE 331 mixer at $200{ }^{\circ} \mathrm{C}$ and $90 \mathrm{rpm}$, during $20 \mathrm{~min}$. To achieve optimum dispersion, clay and coupling agent were incorporated, allowed to mix for $2 \mathrm{~min}$, and then the polymer was added until the end of mixing time. The mixing processing conditions were optimized according to an experimental design. The screw speed varied in order to maximize the exfoliation index which was determined from dynamic shear tests in the linear viscoelastic domain [26]. Then, films were pressed and molded at $160{ }^{\circ} \mathrm{C}$. Pure $P P$ and nanocomposite films were obtained with the same processing conditions to ensure a similar pre-oxidation state.

\section{3. $X R D$}

WAXS measurements were performed in a Philips X'pert MRD diffractometer employing punctual $\mathrm{CuK} \alpha$ radiation at $40 \mathrm{~mA}$ and $40 \mathrm{kV}$ within the scanning angle of $2 \Theta$ from 1.5 to $20^{\circ}$.

\subsection{STEM}

Cross sections of films were thinned down below $100 \mathrm{~nm}$ with a JEOL EM9100IS ion slicer. Scanning Transmission Electron Microscopy, STEM, images of nanocomposite were obtained by using a JEOL 7400F SEM equipped with a STEM accessory at $30 \mathrm{kV}$. Several areas were scanned to ensure that analysis was representative of the sample.

\subsection{Oxygen permeability measurement}

At standard temperature and humidity, $\left(23^{\circ} \mathrm{C}, 50 \%\right.$ humidity), oxygen permeability was measured in an OX-TRAN Model 2/21 MOCON permeameter, having $5.067 \mathrm{~cm}^{2}$ of active area.

\subsection{Thermal aging}

In order to study only the thermal oxidation of non-stabilized samples in the first approach, stabilizers were extracted using a published method [27]. Extracted samples were exposed in aircirculating ovens at atmospheric pressure. The thickness of the film samples used to study the aging kinetics at 60,80 and $100{ }^{\circ} \mathrm{C}$ was $75 \mu \mathrm{m}$. To measure the oxidation profiles, $150 \mu \mathrm{m}$-thick films were used.

\subsubsection{FTIR analysis}

In order to study the growth of carbonyl (CO) bands during thermal oxidation, FTIR measurements were performed by using a Brucker IFS 128 spectrometer in transmission mode, with a resolution of $4 \mathrm{~cm}^{-1}$ between 400 and $4000 \mathrm{~cm}^{-1}$. Concentration of the carbonyl group was determined from the peak absorbance at $1713 \mathrm{~cm}^{-1}$, assuming this peak was assigned to carboxylic acids forming $[28,29]$. According to Beer-Lambert law, the carbonyl concentration is given by.

$[C O]_{a v}=\frac{D O_{c o}}{\varepsilon_{1713} t \rho_{P P}}$

where $[\mathrm{CO}]_{a v}$ is the average carbonyl concentration expressed in mol kg-1 $D O_{c o}$ is the $1713 \mathrm{~cm}^{-1}$ peak absorbance, $t$ is the sample thickness (in $\mathrm{cm}), \rho_{\mathrm{PP}}$ is the polypropylene density $\left(0.90 \mathrm{~kg} \mathrm{l}^{-1}\right)$, and $\varepsilon_{1713}=300 \mathrm{l} \mathrm{mol}^{-1} \mathrm{~cm}^{-1}$ is molar absorptivity. The highest studied average carbonyl concentration was fixed to $[\mathrm{CO}]_{a v}=0.3 \mathrm{~mol} \mathrm{~kg}^{-1}$ because the sample is highly brittle beyond this value [30].

\subsection{Micro ATR-FTIR}

The oxidation profiles were measured with a Perkin-Elmer Spectrum SpotLight 300 ATR-FTIR microscope. The high refractive index of the germanium crystal and an effective sample-crystal contact together permit a $6 \mu \mathrm{m}$ spatial resolution [31]. To acquire an image, both the crystal and the attached sample are moved in the plane of the sample while the infrared beam scans different parts of the sample. Spectra were recorded in reflection mode with steps of $1.56 \mu \mathrm{m}$, which corresponds to the size of the image sample grid. Micro ATR-FTIR spectra were collected using two scans per pixel in a wavenumber range between 4000 and $750 \mathrm{~cm}^{-1}$. Samples were coated with MECAPREX MA2 epoxy resin to improve sample handling and prevent the brittle oxidized layer from being torn off, and then polished under water with polishing paper.

Multiple micro ATR-FTIR spectra were made in the transverse direction of the resin-PP-resin samples. To obtain the oxidation profiles, the integration of the absorption values at $1713 \mathrm{~cm}^{-1}$ was done along the sample thickness. The measured profiles were corrected using a baseline between 1600 and $1850 \mathrm{~cm}^{-1}$, then treated to convert their values from absorbance to concentration units. The relative optic densities were calculated as the ratio between the corrected optic density values on the sample thickness and the corrected absorbance value on the sample surface. 


\section{Results}

\subsection{Material morphology}

To determine the morphology of the nanocomposite WAXS analyses were performed. To assess if the proportion of ethylene in the composite was relevant, presence of the beta phase peaks corresponding to ethylene crystalline structures was verified. Only the characteristic alpha phase peaks corresponding to crystalline $P P$ were present at $14.04^{\circ}$ (Miller index 110) and $16.9^{\circ}$ (Miller index 040). There was no peak at $16^{\circ}$ corresponding to the beta phase, meaning that the quantity of beta phase present in the composite was under the sensitivity limit. A volumic crystallinity close to 0.5 was measured for both materials.

A second $2 \theta$ angle scanning was performed in order to characterize the morphological state in the clay nanocomposite material by measuring the interlayer spacing of the clay before and after the material processing. The spacing variation between clay layers could be directly correlated to filler dispersion through the polymeric matrix. As shown in Fig. 1, the measured nanoclay basal distance was $d_{0}=2.7 \mathrm{~nm}$ and the distance measured after processing was $d=3.1 \mathrm{~nm}$. The difference found between initial and final interlayer distances suggests an intercalated/exfoliated morphology [4]. To qualitatively confirm this affirmation, a STEM study was performed. Fig. 2 shows a STEM image at $120,000 \times$ magnification: the dispersion degree of the clay was characteristic of intercalation with some signs of exfoliation. Aggregates composed of 8 clay sheets, in average, are clearly distinguishable at $500,000 \times$ magnification (Fig. 3).

Based on both WAXS and STEM results, we conclude that the nanocomposite has an intercalated/exfoliated morphology, which corresponds to the most common mixture state reached in materials prepared by the melt intercalation method [32]. Fully exfoliated morphology could be obtained when the nanocomposite was obtained by in situ intercalative polymerization or by intercalation of polymer or pre-polymer from solution methods [17,33].

\subsection{Oxygen permeability}

We were able to measure the oxygen permeability twice for the pure polypropylene and three times for the nanocomposite, only at room temperature. The mean values were $2.28 \times 10^{-17} \mathrm{~m}^{2} \mathrm{~s}^{-1} \mathrm{~Pa}^{-1}$ and $1.17 \times 10^{-17} \mathrm{~m}^{2} \mathrm{~s}^{-1} \mathrm{~Pa}^{-1}$ respectively. We observed a small, although statistically insignificant, difference, due to the low

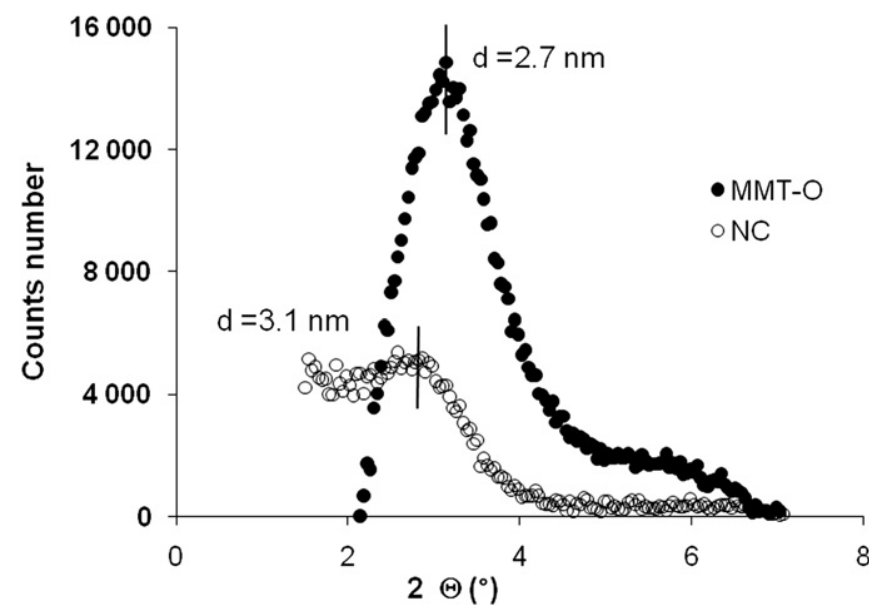

Fig. 1. Differences of count numbers in WAXS tests between pure polypropylene and composite samples.

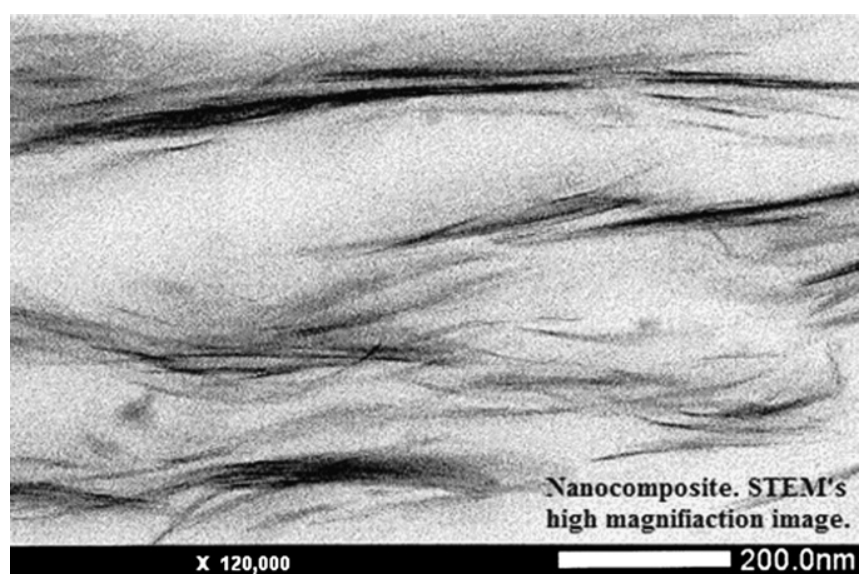

Fig. 2. High magnification STEM image of a film cross section: nanoclay dispersion $120,000 \times$ photograph.

number of tests. Similar results were recently published for a claynanoreinforced polypropylene system which had oxygen permeability improvements between 10 and 40\% [34]. Then, due to the small difference between the oxygen permeabilities of pure $P P$ and nanoreinforced $P P$, the measurement dispersion and the unknown influence of temperature, we applied an inverse method to determine the oxygen diffusion coefficient at $100^{\circ} \mathrm{C}$. This issue is widely discussed in Section 4.3.

\subsection{Characterization of the oxidation process}

IR spectra in the carbonyl region of the matrix (Fig. 4a) and nanocomposite (Fig. 4b) at various oxidation times at $100{ }^{\circ} \mathrm{C}$ reveal the growth of oxidation products. One notices that an extra peak at $1740 \mathrm{~cm}^{-1}$ is initially present in the nanocomposite spectra.

It can be attributed to the presence of saturated aliphatic esters and $\gamma$-lactones $\left(1735-1750 \mathrm{~cm}^{-1}\right)$ due to the organic modification of the montmorillonite.

The thermo-oxidation kinetics were studied at 60,80 and $100{ }^{\circ} \mathrm{C}$ by following the carbonyl appearance as a function of time for the polypropylene and the nanocomposite (Fig. 5). We note that the resulting curves have the typical shape for a given temperature regardless of polymer identity; that is, all curves display an induction stage followed by a short period during which oxidation

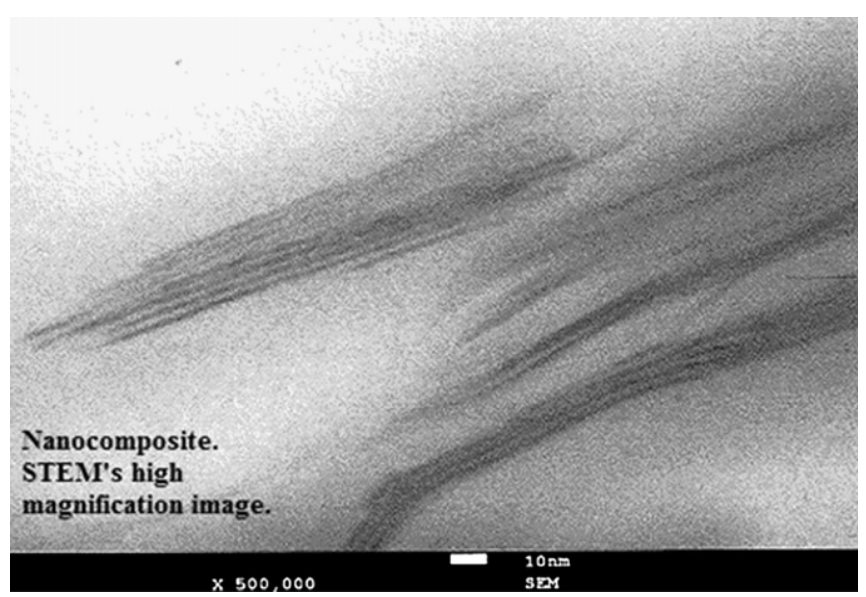

Fig. 3. High magnification STEM image of a film cross section: nanoclay dispersion. $500,000 \mathrm{X}$ photograph. 

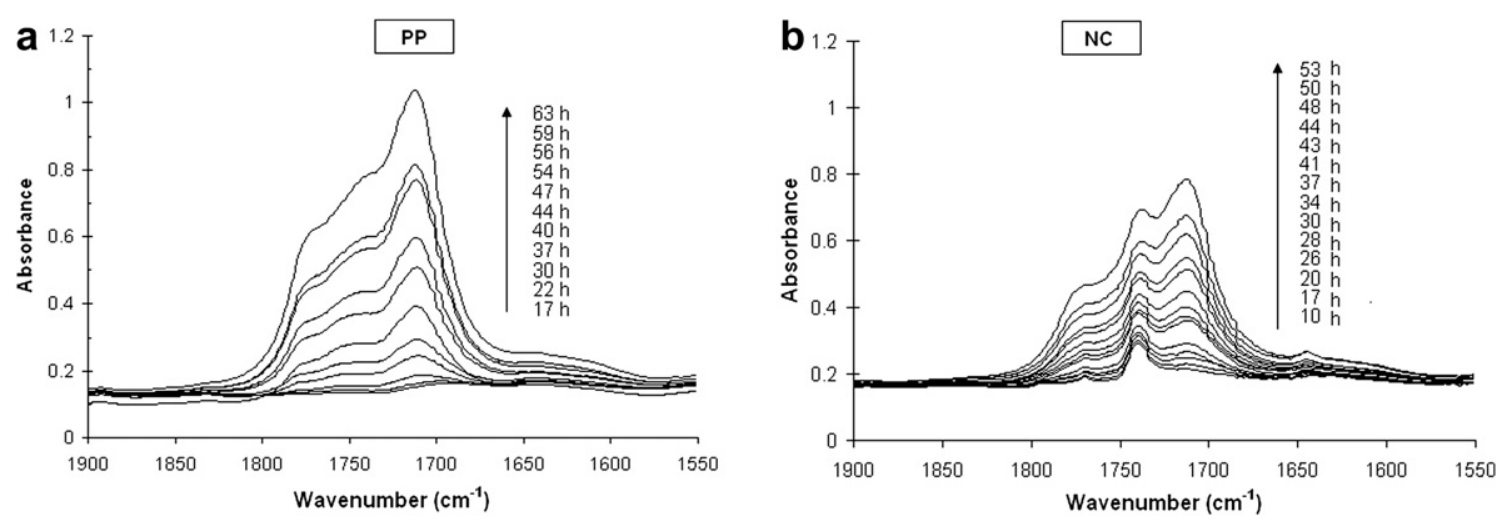

Fig. 4. Evolution of the carbonyl group concentration at $1713 \mathrm{~cm}^{-1}$ and temperature fixed at $100{ }^{\circ} \mathrm{C}$. a) polypropylene, b) nanocomposite.

is strongly auto-accelerated and a steady-state period in which the oxidation rate is almost constant. The induction time $\left(t_{i}\right)$ is commonly used to characterize the oxidation rate. The $t_{i}$ value was experimentally determined by the point at which the straight line corresponding to the steady-state crossed the $t$-axis.

Induction time values for both polymers at the three defined temperatures are included in Table 1. It appears that the induction time values obtained for the nanocomposite are lower for all exposure temperatures, indicating that the nanocomposite is slightly more easily oxidized. The potential causes of this behavior are discussed below.

In the first approach, it was necessary to assess the significance of the induction time difference between both polymers. For this purpose, we plotted in an Arrhenius diagram the induction times of polypropylene and the nanocomposite with compiled literature data (Fig. 6) [35-51]. From this coarse grain point of view, it clearly appears that this difference observed in Table 1 between pure and nanocomposites is not very significant since all induction period values are within the scatter of points corresponding to induction period values reported in the literature. As a result, the nanocomposite can be considered as a pure polypropylene for its oxidation behavior according to this approach. Lastly, we concluded also that the nanofiller has no influence on the activation energy, its average value being close to $116 \mathrm{~kJ} \mathrm{~mol}^{-1}$.

However, the fact that smaller induction times were systematically found for the nanoreinforced materials led us to investigate possible causes to explain the difference between both polymers under study. To explore this divergence more precisely, the carbonyl concentration was plotted as a function of time in a linear scale for an exposure temperature of $100{ }^{\circ} \mathrm{C}$ (Fig. 7). It is noteworthy that if the nanocomposite exhibits a lower induction period as we

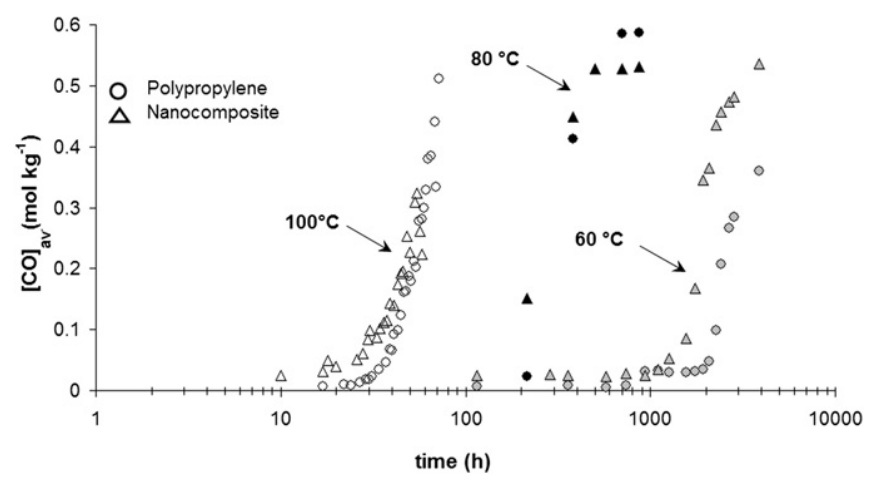

Fig. 5. Kinetic curves of carbonyl build up at 60,80 and $100{ }^{\circ} \mathrm{C}$ for a) pure polypropylene, and b) nanocomposite. have seen before, the nanocomposite also exhibits a lower oxidation rate in the steady-state.

\subsection{Experimental measurement of the oxidation profiles}

Fig. 8a and b show carbonyl profiles for the pure and nanocomposite polypropylene, respectively. On the $y$ axis were plotted the relative absorbances that are the ratio between the absorbance on each point at $1713 \mathrm{~cm}^{-1}$ and the absorbance on the surface of the sample at $1713 \mathrm{~cm}^{-1}$. Such values were corrected by multiplying each absorbance value by the ratio between the absorbance value on the sample surface for $[\mathrm{CO}]_{a v}=0.3 \mathrm{~mol} \mathrm{~kg}^{-1}$ obtained from the simulation and the experimental absorbance value on the sample surface at $[\mathrm{CO}]_{a v}=0.3 \mathrm{~mol} \mathrm{~kg} \mathrm{~kg}^{-1}$. The simulation values were previously corrected by adding the carbonyl concentration measured in transmission mode at time zero before starting the aging process.

It clearly appears that for both materials (Fig. 8) the thickness of the oxidized layer is close to $15 \mu \mathrm{m}$, which means that the oxidation is heterogeneous after the end of the induction period and that the oxidation kinetics are oxygen diffusion limited. To our knowledge, it is the first time that an oxidation profile for PP was measured with such accuracy.

By comparing Fig. 8a and b, it appeared that for the same $[C O]_{a v}=0.3 \mathrm{~mol} \mathrm{~kg}^{-1}$ for instance, the nanocomposite showed a thickness of oxidized layer (TOL) close to $10 \mu \mathrm{m}$ whereas the pure $P P$ TOL is around $17 \mu \mathrm{m}$. Such a difference could be related to the oxygen diffusion. To explore the influence of the oxygen diffusion coefficient on the shape of the oxidation profiles, and especially on the thickness of the oxidation layer, we used an analytical approached which is discussed in Section 4.

\section{Discussion}

To model oxidation behavior of the clay reinforced material, it is necessary to consider the montmorillonite dual influence on the oxidation phenomena. First, the montmorillonite can modify the oxidation mechanism. Second, montmorillonite can affect material physical properties, in particular, the oxygen diffusion coefficient

Table 1

Oxidation induction times for the polypropylene and composite films.

\begin{tabular}{lll}
\hline$T\left({ }^{\circ} \mathrm{C}\right)$ & $t_{\mathrm{i}} \mathrm{PP}(\mathrm{h})$ & $t_{\mathrm{i}} \mathrm{NC}(\mathrm{h})$ \\
\hline 100 & 33 & 25 \\
80 & 220 & 150 \\
60 & 1580 & 1300 \\
\hline
\end{tabular}




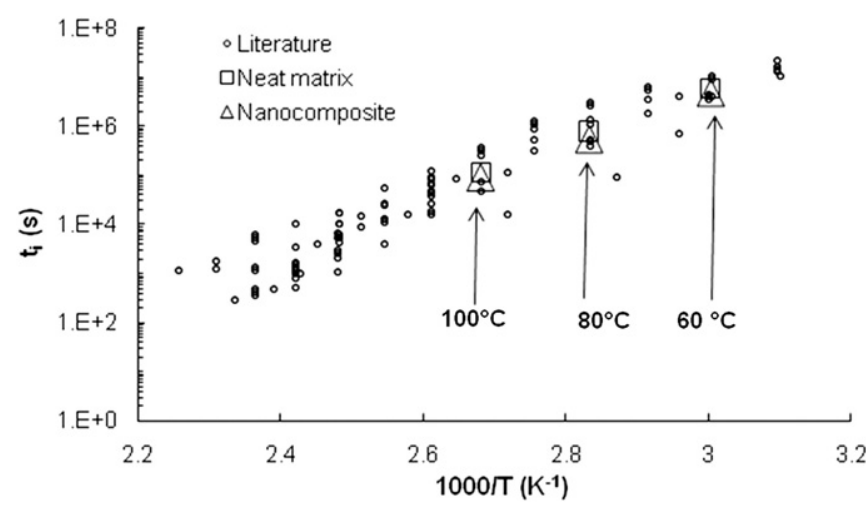

Fig. 6. Arrhenius dependence for induction times $\left(t_{i}\right)$ at 60,80 and $100{ }^{\circ} \mathrm{C}$ for the pure polypropylene and nanocomposite.

and the reaction-diffusion coupling. Both chemical and physical influences of montmorillonite are studied in this work. Section 4.1 presents the kinetic model used to simulate the oxidation behavior of the nanocomposite. In Section 4.2, model parameters and comparison between the model predictions and experimental results are discussed. Section 4.3 is dedicated to the discussion of the influence of oxygen diffusion coefficient variations on oxidation profiles as a function of sample thickness.

\subsection{Kinetic modelling}

The Closed Loop Model (CLM) was used to model oxidation kinetics [16]. The model is derived from a standard mechanistic scheme in which oxidation results from a chain reaction initiated by hydroperoxide decomposition. Alkyl $\left(\mathrm{P}^{*}\right)$ and peroxyl $\left(\mathrm{PO}_{2}^{*}\right)$ radicals are the chain carriers. The three possible terminations between these radicals are taken into account. The predictive power of this model is now well established [14-16].

For the general case where termination may occur by bimolecular reactions, the closed-loop mechanistic scheme involves seven elementary reactions:

Initiation

$\mathrm{POOH} \rightarrow 2 \mathrm{P}^{\bullet}+\mathrm{H}_{2} \mathrm{O}+\mathrm{P}=\mathrm{O} \quad$ Unimolecular

$2 \mathrm{POOH} \rightarrow \mathrm{P}^{\circ}+\mathrm{PO}_{2}^{\cdot}+\mathrm{H}_{2} \mathrm{O}+\mathrm{P}=\mathrm{O} \quad$ Bimolecular

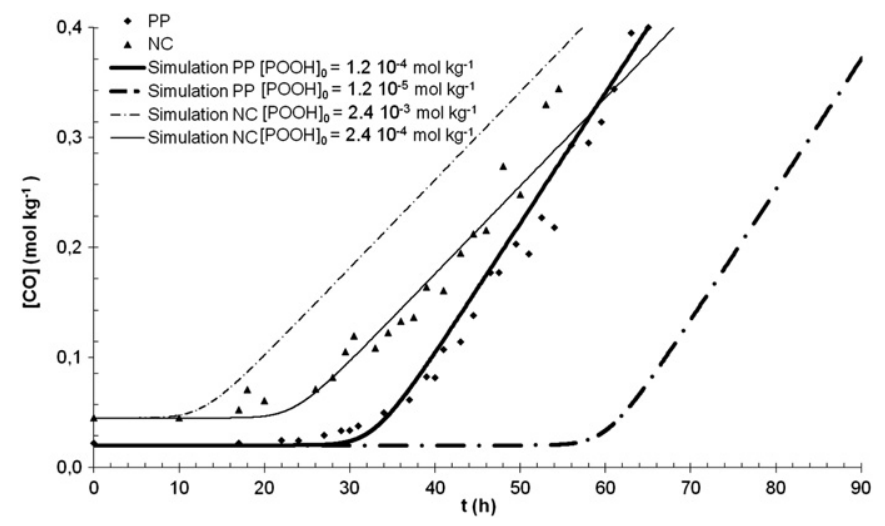

Fig. 7. Comparison between experimental data and simulation kinetic curves at $100{ }^{\circ} \mathrm{C}$ and $[\mathrm{POOH}]_{0}$ influence on kinetic curves: $[\mathrm{POOH}]_{O N C}: 2.4 \times 10^{-3}$ and $2.4 \times 10^{-4} \mathrm{~mol}$ $\mathrm{kg}^{-1},[\mathrm{POOH}]_{O P P}: 1.2 \times 10^{-4}$ and $1.2 \times 10^{-5} \mathrm{~mol} \mathrm{~kg}{ }^{-1}$.
Propagation

$\mathrm{P}^{\bullet}+\mathrm{O}_{2} \rightarrow \mathrm{PO}_{2}^{\circ}$

$\mathrm{PO}_{2}^{\circ}+\mathrm{PH} \rightarrow \mathrm{POOH}+P^{\cdot}$

Termination

$P^{\bullet}+P^{\bullet} \rightarrow$ Inactive products

$P^{\bullet}+\mathrm{PO}_{2}^{\circ} \rightarrow$ Inactive products

$\mathrm{PO}_{2}^{\circ}+\mathrm{PO}_{2}^{\circ} \rightarrow$ Inactive products

A set of ordinary differential equations is derived from this scheme; it expresses the concentration changes of the involved reactive species. Equations (2)-(4) correspond to the alkyl radical $\left(\mathrm{P}^{*}\right)$, peroxyl radical $\left(\mathrm{PO}_{2}^{*}\right)$, and hydroperoxide $(\mathrm{POOH})$ concentrations respectively, and $k_{1 \mathrm{u}}, k_{1 \mathrm{~b}}, k_{2}, k_{3}, k_{4}, k_{5}$, and $k_{6}$ are rate constants for reactions (I)-(VI).

$$
\begin{aligned}
\frac{\mathrm{d}\left[\mathrm{P}^{*}\right]}{\mathrm{d} t}= & 2 k_{1 u}[\mathrm{POOH}]+k_{1 b}[\mathrm{POOH}]^{2}-k_{2}\left[\mathrm{P}^{*}\right]\left[\mathrm{O}_{2}\right]+k_{3}\left[\mathrm{PO}_{2}^{*}\right][\mathrm{PH}] \\
& -2 k_{4}\left[\mathrm{P}^{*}\right]^{2}-k_{5}\left[\mathrm{P}^{*}\right]\left[\mathrm{PO}_{2}^{*}\right]
\end{aligned}
$$

$\begin{aligned} \frac{\mathrm{d}\left[\mathrm{PO}_{2}^{*}\right]}{\mathrm{d} t}= & k_{1 b}[\mathrm{POOH}]^{2}+k_{2}\left[\mathrm{P}^{\bullet}\right]\left[\mathrm{O}_{2}\right]-k_{3}\left[\mathrm{PO}_{2}^{*}\right][\mathrm{PH}]-k_{5}\left[\mathrm{P}^{\bullet}\right]\left[\mathrm{PO}_{2}^{\cdot}\right] \\ & -2 k_{6}\left[\mathrm{PO}_{2}^{\cdot}\right]\end{aligned}$

$\frac{\mathrm{d}[\mathrm{POOH}]}{\mathrm{d} t}=-k_{1 u}[\mathrm{POOH}]-2 k_{1 b}[\mathrm{POOH}]^{2}+k_{3}\left[\mathrm{PO}_{2}^{\cdot}\right][\mathrm{PH}]$

The initial and boundary conditions input to solve the system of differential equation were $\left[\mathrm{PO}_{2}^{*}\right]=0,\left[\mathrm{P}^{*}\right]=0,[\mathrm{POOH}]=[\mathrm{POOH}]_{0}$, $[\mathrm{PH}]=[\mathrm{PH}]_{0},\left[\mathrm{O}_{2}\right]=\left[\mathrm{O}_{2}\right]_{s}$, where $[\mathrm{PH}]_{0}$ and $\left[\mathrm{O}_{2}\right]_{s}$ are the initial concentrations of the $[\mathrm{PH}]$ and $\left[\mathrm{O}_{2}\right]$ species respectively (see Table 3 ).

The oxygen diffusion effect could also be included in the CLM by adding the oxygen diffusion term (Equation (5)). $D_{\mathrm{O}_{2}}$ is the coefficient of oxygen diffusion in the polymer. This coefficient is lower in the nanocomposite than in the pure matrix.

$\left.\frac{\mathrm{d}\left[\mathrm{O}_{2}\right]}{\mathrm{d} t}=D_{\mathrm{O}_{2}} \frac{\partial^{2}\left[\mathrm{O}_{2}\right]}{\partial^{2} \chi^{2}}\right)-k_{2}\left[P^{*}\right]\left[\mathrm{O}_{2}\right]+k_{6}\left[\mathrm{PO}_{2}^{*}\right]^{2}$

The CLM input is completed by adding an extra condition related to the oxygen diffusion: at any time, $\left[\mathrm{O}_{2}\right]=\left[\mathrm{O}_{2}\right]_{s}$ for $x=-L / 2$ and $x=L / 2$, the origin of depth coordinates being taken in the middle of the sample thickness.

Assuming that the source of the carbonyl group (CO) is the decomposition of hydroperoxides, carbonyl concentration $[\mathrm{CO}]_{a v}$ is written as:

$\frac{\mathrm{d}[\mathrm{CO}]_{a v}}{\mathrm{~d} t}=\left[k_{1 u}[\mathrm{POOH}]+k_{1 b}[\mathrm{POOH}]^{2}\right] \times\left[1-X_{c}-M M T\right] \times \rho_{P P}^{-1}$

where $X_{c}$ is the crystallinity ratio of the sample expressed in volume fraction $\left(X_{c}=0.5\right)$, and $M M T-O$ is the volume fraction of montmorillonite equal to 0.08 in our case. Since oxidation occurs only in the amorphous phase, the $X_{c}$ and $M M T-O$ terms were included in Equation (6) as correction factors related to the amorphous phase fraction present in the polymer in which oxidation occurs. The 

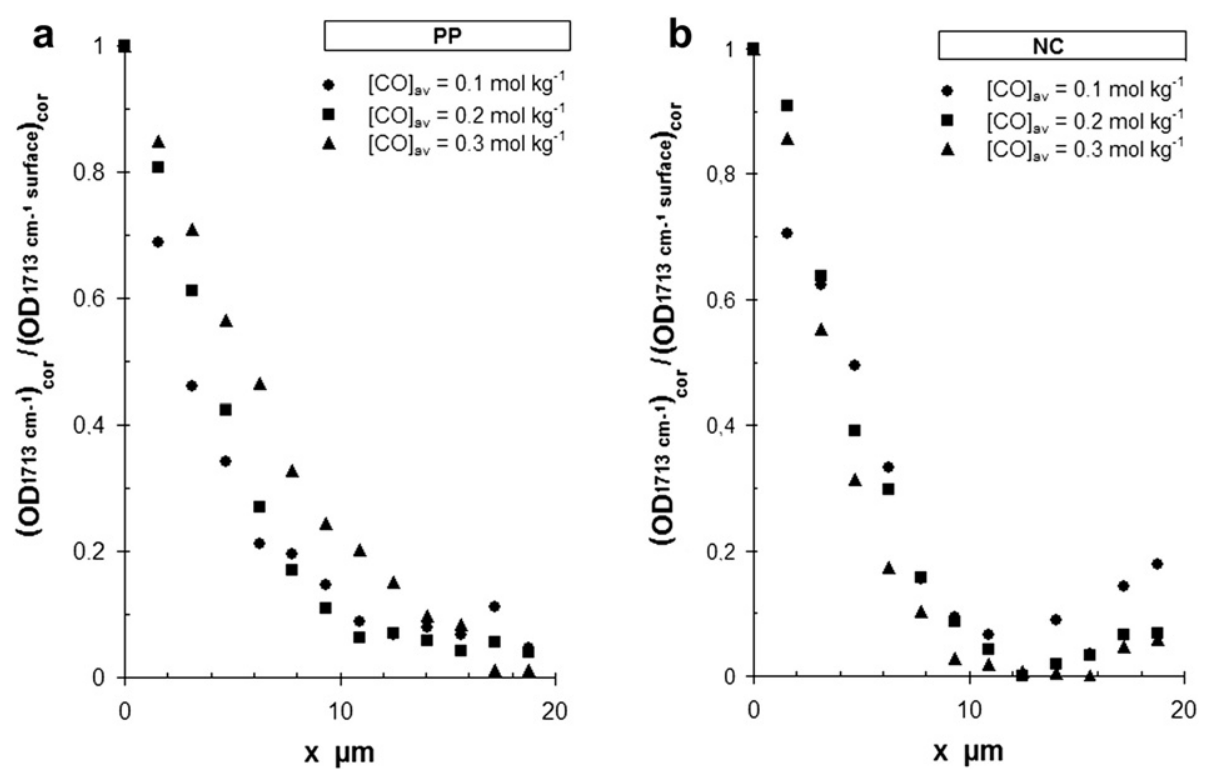

Fig. 8. Relative optic density (OD) at $1713 \mathrm{~cm}^{-1}$ of the experimental oxidation profiles at $[C O]_{a v}=0.1,0.2$ and $0.3 \mathrm{~mol} \mathrm{~kg}^{-1}$ for a) pure polypropylene b) nanocomposite.

kinetic parameters' values for pure polypropylene at $100{ }^{\circ} \mathrm{C}$ reported by Richaud [52] are shown in Table 2.

\subsection{Carbonyl build-up simulation}

The initial hydroperoxide concentration $[\mathrm{POOH}]_{0}$ can be considered as the initial $\mathrm{POOH}$ concentration kinetically equivalent to the concentration of all the radical sources initially present in the material. Its value is generally lower than the sensitivity threshold of available titration methods. It appears thus as an adjustable parameter of the kinetic model. To illustrate the sensitivity of the model to changes of this parameter, simulated carbonyl growth curves are included in Fig. 7 adjusting $[\mathrm{POOH}]_{0}$ values for both pure and reinforced polypropylene to fit experimental carbonyl growth curves in Fig. 7. After optimization, we selected for the pure and reinforced polypropylene $[\mathrm{POOH}]_{O P P}=1.2 \times 10^{-4} \mathrm{~mol} \mathrm{~kg}^{-1}$, and $[P O O H]_{\text {ONC }}=2.4 \times 10^{-4} \mathrm{~mol} \mathrm{~kg}^{-1}$ respectively to achieve a good agreement between the experimental and simulated $\mathrm{CO}$ values (Table 3).

These results can be interpreted as follows: Montmorillonite exerts a direct (catalytic effect by metallic impurities) or indirect (thermomechanic history during processing) small influence on nanocomposite pre-oxidation, leading to the reduction of the induction time. A similar effect has been observed from the presence of residual Ziegler-Natta catalyst Titanium [53]. As a result, the initial hydroperoxide concentration $[\mathrm{POOH}]_{0}$ is slightly higher in the nanocomposite than in the pure polymer, which explains the observed difference in the oxidation behavior. It is noteworthy that a slight catalytic effect of montmorillonite on PP photooxidation was already reported in the case of intercalated and exfoliated samples [10,54].

The steady-state behavior is well simulated without parameter modifications (Fig. 7). The disparity between PP and the nanocomposite is only due to the difference in the amorphous phase concentration (see Equation (6)). We recall that in a closed-loop process, the steady-state behavior is independent of the initiation rate and the $[\mathrm{POOH}]_{0}$ value. Experimental observations are thus in good agreement with theoretical prediction.

\subsection{Oxidation controlled by diffusion}

When the oxidation process is controlled by oxygen diffusion, oxidation rate and oxygen diffusion competition leads to an oxidation profile formation. In other words, oxidation is likely confined to a superficial layer when film thickness is higher than $20 \mu \mathrm{m}$ as predicted by [15]. According to the measured oxidation profiles (Fig. 8a and b), there is a difference between the thickness of the pure polypropylene and the oxidized nanocomposite layer. In that case, it should be possible to describe the oxidation behavior of both materials using the oxygen diffusion coefficient as fitting variable, which will be different for each material. Since permeation tests displayed relatively high uncertainty, we decided to determine the oxygen diffusion coefficients of pure and nanoreinforced polypropylene from the kinetic model, using an inverse method.

Fig. 9 illustrates the influence of oxygen diffusion coefficient value on the oxidation profile shape at $100{ }^{\circ} \mathrm{C}$ and a $[\mathrm{CO}]_{a v}$ equal to $0.3 \mathrm{~mol} \mathrm{~kg}^{-1}$ for the pure polypropylene. Several oxygen diffusion coefficient values $D_{\mathrm{O}_{2}}$ ranging from $2 \times 10^{-13} \mathrm{~m}^{2} \mathrm{~s}^{-1}$ and $2.0 \times 10^{-11} \mathrm{~m}^{2} \mathrm{~s}^{-1}$ were used in simulation. It is noticeable that for such $D_{\mathrm{O}_{2}}$ values, the profile shape radically changes: high $D_{\mathrm{O}_{2}}$ generates wide profiles, but for smaller values of $D_{\mathrm{O}_{2}}$ the obtained oxidation profiles are narrowed. It is clear that the kinetic model is sensitive enough to discern small changes in $D_{\mathrm{O}_{2}}$ and their influence on the shape of the oxidation profiles. In this way it was possible to identify the oxygen coefficient value for each of the materials, and $D_{\mathrm{O}_{2}}=2.0 \times 10^{-12} \mathrm{~m}^{2} \mathrm{~s}^{-1}$ and $1.2 \times 10^{-12} \mathrm{~m}^{2} \mathrm{~s}^{-1}$ were found for the polypropylene and the nanocomposite respectively (Table 3).

Table 2

Kinetic constants of the kinetic closed loop model.

\begin{tabular}{|c|c|c|c|c|c|c|c|}
\hline$T\left({ }^{\circ} \mathrm{C}\right)$ & $k_{1 \mathrm{u}}\left(\mathrm{s}^{-1}\right)$ & $k_{1 \mathrm{~b}}\left(1 \mathrm{~mol} \mathrm{~s}^{-1}\right)$ & $k_{2}\left(1 \mathrm{~mol} \mathrm{~s}^{-1}\right)$ & $k_{3}\left(1 \mathrm{~mol} \mathrm{~s}^{-1}\right)$ & $k_{4}\left(1 \mathrm{~mol} \mathrm{~s}^{-1}\right)$ & $k_{5}\left(1 \mathrm{~mol} \mathrm{~s}^{-1}\right)$ & $k_{6}\left(1 \mathrm{~mol} \mathrm{~s}^{-1}\right)$ \\
\hline 100 & $1.5 \times 10^{-7}$ & $1.0 \times 10^{-4}$ & $1.3 \times 10^{7}$ & $7.0 \times 10^{-1}$ & $1.0 \times 10^{10}$ & $2.6 \times 10^{9}$ & $3.0 \times 10^{3}$ \\
\hline
\end{tabular}


Table 3

Material parameters for the kinetic closed loop model.

\begin{tabular}{lllllll}
\hline & $\begin{array}{l}{[\mathrm{PH}]_{0}} \\
\left(\mathrm{~mol} \mathrm{l}^{-1}\right)\end{array}$ & $\begin{array}{l}{[\mathrm{POOH}]_{O}} \\
\left(\mathrm{~mol} \mathrm{l}^{-1}\right)\end{array}$ & $X_{c}$ & $M M T-O$ & $\begin{array}{l}S_{\mathrm{O}_{2}} \\
\left(\mathrm{~mol} \mathrm{l}^{-1} \mathrm{~Pa}^{-1}\right)\end{array}$ & $\begin{array}{l}D_{\mathrm{O}_{2}} \text { at } 100{ }^{\circ} \mathrm{C} \\
\left(\mathrm{m}^{2} \mathrm{~s}^{-1}\right)\end{array}$ \\
\hline PP & 20 & $1.2 \times 10^{-4}$ & 0.5 & 0 & $1.15 \times 10^{-7}$ & $2.0 \times 10^{-12}$ \\
NC & 20 & $2.4 \times 10^{-4}$ & 0.5 & 0.1 & $1.15 \times 10^{-7}$ & $1.2 \times 10^{-12}$ \\
\hline
\end{tabular}

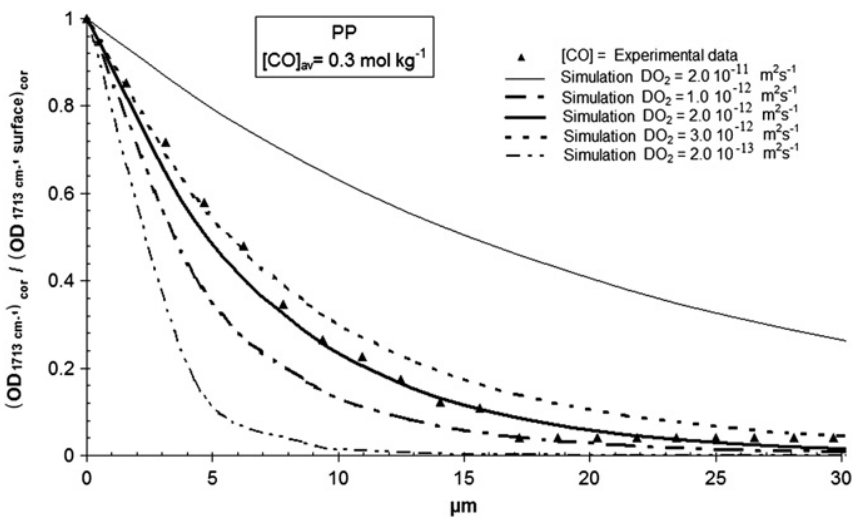

Fig. 9. Influence of the oxygen diffusion coefficient $D_{\mathrm{O}_{2}}$ variation on the simulated carbonyl distribution in the thickness of $150 \mu \mathrm{m}$-thick PP films at $[\mathrm{CO}]_{a v}=0.3 \mathrm{~mol} \mathrm{~kg}^{-1}$.

Fig. 10 shows the theoretical and experimental oxidation profiles in mol kg-1 for three different exposure times, corresponding to the average concentration in the whole thickness of the film $[C O]_{a v}=0.1,0.2$, and $0.3 \mathrm{~mol} \mathrm{~kg}^{-1}$. These concentrations were measured in transmission mode using the Beer-Lambert law. The integration values of $[\mathrm{CO}]_{a v}$ along the $150 \mu \mathrm{m}$-sample thickness were taken from the $y$-axes of Fig. 10a and b. Experimental values were treated using a single adjusting factor equal to the experimental absorbance in the sample thickness to the simulated $[\mathrm{CO}]_{a v}$ on the sample surface for an average carbonyl concentration of $[C O]_{a v}=0.3 \mathrm{~mol} \mathrm{~kg}^{-1}$ Fig. 10a and b display the last $20 \mu \mathrm{m}$ (from the surface) of pure and nanocomposite polypropylene cross sections, respectively.

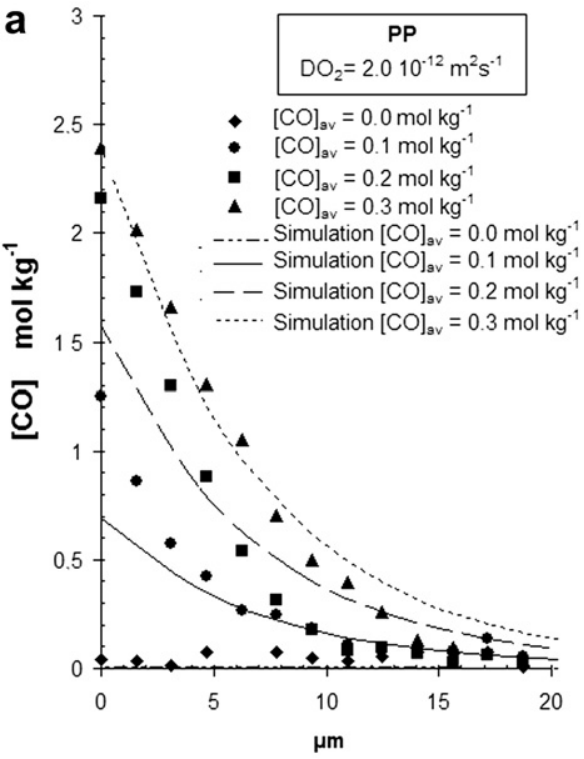

As shown in Fig. 10, a good agreement between simulation and experimental data was obtained by using for pure polypropylene, $D_{\mathrm{O}_{2} P \mathrm{P}}: 2.0 \times 10^{-12} \mathrm{~m}^{2} \mathrm{~s}^{-1}$ and for nanocomposite, $D_{\mathrm{O}_{2} \mathrm{NC}}: 1.2 \times 10^{-12} \mathrm{~m}^{2} \mathrm{~s}^{-1}$. Some noise was found in the profile simulation of the nanocomposite; this is attributed to mixing effects related to the clay dispersion in the matrix and to the quality of the sample surface when the ATR testing was performed.

Since the TOL was $17 \mu \mathrm{m}$ for the $P P$ and $10 \mu \mathrm{m}$ for the nanocomposite, it is important to point out that the TOL results from the competition between the oxidation rate and $\mathrm{O}_{2}$ diffusion (see kinetic model where the differential equations included oxidation and Fick $\mathrm{O}_{2}$ diffusion). However, there is no theoretical reason to assume that nanofillers increase the oxidation rate since this property is linked to the propagation $\left(k_{3}\right)$ and termination $\left(k_{6}\right)$ steps of the oxidation mechanism and the amorphous phase content. This may be why nanofillers act only as "defects," leading to a decreased induction period (increase of $[\mathrm{POOH}]_{O}$ in the modeling). Furthermore, in Fig. 7, the experimental oxidation rate corresponding to the slope of $[\mathrm{CO}]_{a v}$ build-up after the induction period measured on thin films ( $75 \mu \mathrm{m}$ ) shows a decrease in the case of $N C$ compared to $P P$ which is explained by the decrease of the amorphous phase content. At last, from the modeling point of view, an oxidation rate increase (by increasing $k_{3}$ for instance) does not contribute to a good description of the oxidation profiles. As a result, the simulated profile curves are unique for a good fit of all experimental data (carbonyl build-up and profiles).

\section{Conclusions}

Thermal oxidation of pure polypropylene and its nanocomposite was studied experimentally and simulated with a kinetic model The first objective of this study was to determine possible effects of montmorillonite on the oxidation kinetic behavior of polypropylene at moderate temperatures. Slight differences between induction times of polypropylene and its nanocomposite were found. They can be attributed to a presumed catalytic effect of montmorillonite impurities on PP oxidation or simply to a difference in thermomechanical histories between $P P$ and the nanocomposite. From a modeling point of view, this effect can be taken

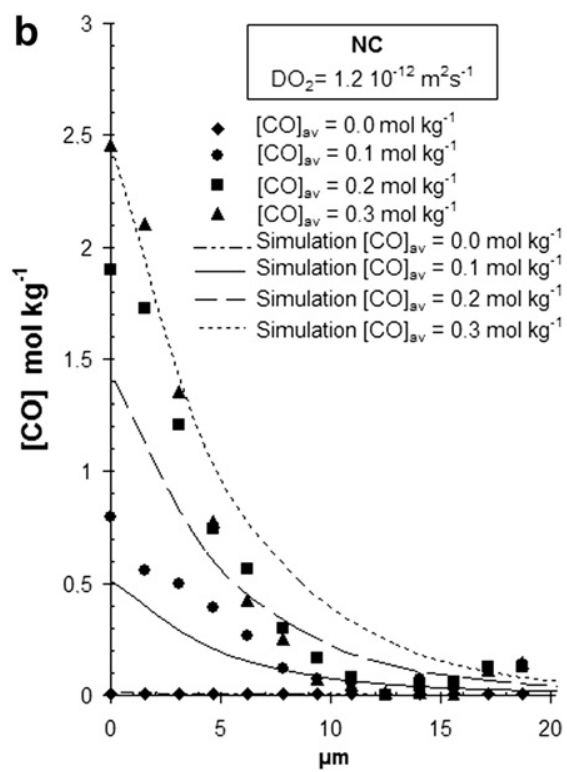

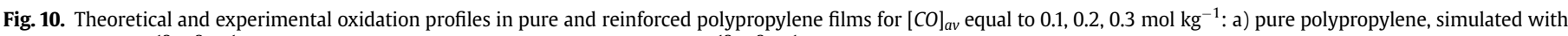
$D_{\mathrm{O}_{2} P P}: 2.0 \times 10^{-12} \mathrm{~m}^{2} \mathrm{~s}^{-1}$. b) Nanocomposite, simulated with $D_{\mathrm{O}_{2} \mathrm{NC}}: 1.2 \times 10^{-12} \mathrm{~m}^{2} \mathrm{~s}^{-1}$. 
into account by increasing initial hydroperoxide concentration $[\mathrm{POOH}]_{0}$. As a result, montmorillonite could be considered as a filler which leads an oxidation rate increase only during the induction period.

The second objective was to study the physical influence of montmorillonite in polypropylene and its effect on oxidation profiles. By using the ATR-FTIR microscope, evidence was obtained that the oxidized layer thickness is close to $17 \mu \mathrm{m}$ for pure polypropylene and $10 \mu \mathrm{m}$ for the nanocomposite for an exposure at $100{ }^{\circ} \mathrm{C}$. This difference has been attributed to the decrease of the oxygen diffusion coefficient by adding montmorillonite. This hypothesis was examined by simulating carbonyl profiles. A good agreement between experimental and simulated profiles was obtained by using an oxygen diffusion coefficient value $\left(D_{\mathrm{O}_{2}}\right)$ for the nanocomposite $40 \%$ smaller than that for pure polypropylene.

\section{References}

[1] Chatterjee A, Deopura BL. High modulus and high strength PP. Comp Part A 2006;37:813-7.

[2] Tabtiang A, Venables R. The performance of selected unsaturated coatings for calcium carbonate filler in polypropylene. Eur Polym J 2000;36:137-48.

[3] Tidjani A, Wilkie A. Photo-oxidation of polymeric-inorganic nanocomposites: chemical, thermal stability and fire retardancy investigations. Polym Degrad Stab 2001;74:33-7.

[4] Aloisi G, Costantino U, Latterini L, Nocchetti N, Camino G, Frache A. Preparation and spectroscopic characterization of intercalation products of clay and of clay-polypropylene composites with rhodamine B. J Phys Chem Sol 2006;67:909-14.

[5] Benetti M, Causin V, Marega C, Marigo A, Ferrara G, Ferraro A, et al Morphological and structural characterization of polypropylene based nanocomposites. Polymer 2005;46:8275-85.

[6] Rong M, Zhang M, Zheng Y, Zeng H, Walter F. Structure-property relationships of irradiation grafted nano-inorganic particle filled polypropylene composites. Polymer 2001;42:167-83.

[7] Vaia R, Giannelis E. Polymer melt intercalation in organically-modified layered. Macromolecules 1997;30:8000-9.

[8] Qin H, Zhang Z, Feng M, Gong F, Zhang S, Yang M. The Influence of interlayer cations on the photo-oxidative degradation of polyethylene/montmorillonite composites. J Polym Sci Part B Polym Phys 2004:42:3006-12.

[9] Qin O, Zhang C, Liu H, Xie S, Yang M, Shen D. Photo-oxidative degradation of polypropylene/montmorillonite nanocomposites. Polymer 2005;46:3149-56.

[10] Mailhot B, Morlat S, Gardette JL, Boucard, Duchet J, Gerard JF. Photodegradation of polypropylene nanocomposites. Polym Degrad Stab 2003;82:163-7.

[11] Lomakin S, Dubnikova I, Berezina S. Kinetic study of polypropylene nanocomposite thermo-oxidative degradation. Polym Int; 2005:999-1006.

[12] Vyazovkin S, Dranca I, Fan X, Advincula R. Kinetics of the thermal and thermo - oxidative degradation of a polystyrene-clay nanocomposite. Macromol Rapid Commun 2004;25:498-503.

[13] Bertini F, Canetti M, Audisio G, Costa G, Falqui L. Characterization and therma degradation of polypropylene-montmorillonite nanocomposites. Polym Degrad Stab 2006;91:600-5.

[14] Colin X, Verdu J. Strategy for studying thermal oxidation of organic matrix composites. Compos Sci Technol 2005;65:411-9.

[15] Rincon LM, Fayolle B, Audouin L, Verdu JA. General solution of the closed-loop kinetic scheme for the thermal oxidation of polypropylene. Polym Degrad Stab 2001;74:177-88.

[16] Richaud E, Farcas F, Bartolomeo P, Fayolle B, Audouin L, Verdu J. Effect of oxygen pressure on the oxidation kinetics of unstabilised polypropylene. Polym Degrad Stab 2006;91:398-405.

[17] Boucard S, Duchet J, Gérard JF, Prele P, Gonzales S. Processing of polypropylene - clay hybrids. Macromol Symp 2003;194:241-6.

[18] Cerruti P, Laurinzo P, Malinconio M, Carfagna C. Thermal oxidative stability and effect of water on gas transport and mechanical properties in PA6-EVOH films. J Polym Sci Part B 2007;45:840-9.

[19] Fayolle B, Verdu J, Bastard M, Piccoz D. Thermooxidative ageing of polyoxymethylene, part1: chemical aspects. J Appl Polym Sci 2008;107:1783-92.
[20] Dumas P, Carr GL, Williams GP. Enhancing the lateral resolution in infrared microspectometry by using synchrotron radiation: applications and perspectives. Analusis 2000;28(No. 1):68-74.

[21] Do T, Celina M, Fredericks P. Attenuated total reflectance infrared microspectroscopy of aged carbon - filled rubbers. Polym Degrad Stab 2002;77: 417-22.

[22] Küpper L, Gulmine JV, Janissek PR, Heise HM. Attenuated total reflection infrared spectroscopy for micro-domain analysis of polyethylene samples after accelerated ageing within watering chambers. Vib Spectrosc 2004;34: 63-72.

[23] Dhoot G, Auras R, Rubino M, Dolan K, Soto-Valdez H. Determination of eugenol diffusion through LLDPE using FTIR-ATR flow cell and HPLC techniques. Polymer 2009;50:1470-82.

[24] Flemming O, Chan A, Kazarian S. High-pressure $\mathrm{CO}_{2}$-enhanced polymer interdiffusion and dissolution studied whit in situ FTIR-ATR spectroscopic imaging. Polymer 2006;47:4649-58.

[25] Zhou X, Zhang P, Jiang X, Rao G. Influence of maleic anhydride grafted polypropylene on the miscibility of polypropylene/polyamide- 6 blends using ATRFTIR mapping. Vib Spectrosc 2009;40:17-21.

[26] Gutiérrez G, Regnier G, Medina J. Exfoliation index as viscoelastic tool to characterize the structure of clay nano-reinforced polypropylenes. Macromolecules Symposium World Polymer Congress. Rio de Janeiro, Brazil: WileyVCH Verlag Gmbh \& Co; 2006. p. 245-246.

[27] Zahradnickova A, Sedlar J, Dastych D. Peroxy acids in photo-oxidized polypropylene. Polym Degrad Stab 1991;32:155-76.

[28] Gugumus F. Thermooxidative degradation of polyolefins in the solid state: Part 1. Experimental Kinetics of Functional Group Formation. Polym Degrad Stab; 1996:131-44.

[29] Delprat P, Deteurtre X, Gardette JL. Photooxidation of unstabilized and HALSstabilized polyphasic ethylene-propylene polymers. Polym Degrad Stab 1995; $50: 1-12$

[30] Fayolle B, Audouin L, Verdu J. Initial Steps and Embrittlement in the thermal oxidation of stabilised polypropylene films. Polym Degrad Stab 2002;75: 123-9.

[31] PerkinElmer Ltd. ATR imaging accessory User's Guide; 2006.

[32] Morgan A, Gilman J. Characterization of polymer-layered silicate (clay) nanocomposites by transmission electron microscopy and x-ray diffraction: a comparative study. J Appl Polym Sci 2003;87:1329-38.

[33] Shina R, Okamoto M. Polymer:layered silicate nanocomposites/a review from preparation to processing. Prog Polym Sci 2003;28:1539-641.

[34] Golebiewsky J, Galeski A. Thermal stability of nanoclay polypropylene composites by simultaneous SDC and TGA. Comp Sci Tech 2007;67: 3442-7.

[35] Gijsman P, Hennekens J, Vincent J. Polym Degrad Stab 1993;39:271-7.

[36] Roginsky VA. In developments in polymer degradation -5. Applied Science Publishers; 1984. Chap. 6, p. 193-225.

[37] Meltzer TH, Kelley JJ, Goldey RNJ. Appl Polym Sci 1960;3:84-9.

[38] Iring M, Laszlo-Hedvig S, Barabas K, Kelen T, Tudos F. Eur Polym J 1978; $14: 439-42$

[39] Tudos F., Iring M., Kelen T., Int. Conf. On Adv. In the Stab. And Contr. Degrad. of Polym (1); 1984. p. 86-98.

[40] Hansen RH, Russell CA, De Benedictis T, Martin NM, Pascale JV. J Polym Sci 1964;A2:587

[41] Chien JC, Boss CR. J Polym Sci 1967;5:3091.

[42] Achimsky L, Audouin L, Verdu J, Rychly J, Matisova-Rychla L. Polym Degrad Stab 1997;58:283-9.

[43] Hawkins WL, Matreyek W, Winslow FH. J Polym Sci 1959;41:1-11.

[44] Schwarz T, Steiner G, Koppelmann J. J Appl Polym Sci 1989;38:1-7.

[45] Al-Malaika S, Scott G, Huczkowski P. Polym Degrad Stab 1984;7:95-107.

[46] Billingham NC. Makromol Chem, Macromol Symp 1989;28:145-63.

[47] Billingham N.C, Calvert P.D. In Developments in Polymer Stabilisation-3, Chap. 5. p. $97-139$.

[48] Billingham NC, Prentice P, Walker TJ. J Polym Sci 1976;57:287-97.

[49] Boss CR, Chien JC. J Polym Sci Part A1 1966;4:1543-51.

[50] Al-Malaika S. Polym Degrad Stab 1991;34:1-36.

[51] Osawa Z, Shibamiya T, Matsuzaki K. Kogyo Kagaku Zasshi (Japan) 1968: 71:552.

[52] Richaud E. Durabilité des géotexiles en polypropylène. PhD thesis, Ecole Nationale Supérieure d'Arts et Métiers - Centre de Paris; 2006.

[53] Goss BGS, Nakatani H, George GA, Teranoa M. Polym Degrad Stab 2003;82: 119-26.

[54] Morlat S, Mailhot B, Gardette J, Da Silva C, Haidar B, Vidal A. Polym Degrad Stab 2005;90:78-85. 